\title{
A NORMATIVIDADE DOS PRINCÍPIOS NA CONSTITUCIONALIZAÇÃO DO DIREITO
}

André Almeida Nelvam ${ }^{1}$

\section{Resumo}

O presente artigo tem como objetivo analisar as diferenças entre a normatividade dos princípios e regras, conforme critérios de distinção apontados pelas teorias que adotam esta divisão e relacioná-las como mecanismo da constitucionalização do direito. Para tanto, além dos critérios de distinção, é descrita a evolução das concepções sob as quais os princípios se desenvolveram: jusnaturalismo, positivismo e pós-positivismo. Em seguida, buscando distinguir fontes determinantes à concretização normativa, são analisados o texto normativo, a materialidade e a interpretação. Para tanto são consideradas a Teoria Estruturante do Direito de Friedrich Müller e a ontologia de Heidegger. Feitas as considerações gerais sobre a estrutura das normas, são apontadas algumas características específicas das normas constitucionais e do seu ramo jurídico. Por fim, a conclusão procura verificar a compatibilidade entre a conceituação dos princípios como espécie de norma e sua influência na interpretação e concretização do Direito Constitucional.

Palavras Chave: Normatividade. Princípios. Materialidade. Teoria Estruturante. Constitucionalização.

\section{INTRODUÇÃO}

Uma das discussões mais instigantes no meio jurídico, tanto acadêmico quanto judicial, que tem atraído os olhares e esforços dos doutrinadores em todo o mundo, versa sobre a natureza dos princípios constitucionais e sua concepção como norma jurídica.

Historicamente, passaram os princípios por várias fases até atingir o status de norma, assim considerados pela ciência jurídica. Contudo, não obstante, suas características ainda carecem de clarificação, exigindo esforços dos aplicadores na sua realização e tendo como consequência a insegurança dos seus efeitos, pela ausência de uma teoria que estruture sua aplicação a ponto de controlar a atividade do aplicador.

Tratando-se da constitucionalização dos ramos do direito, principalmente por meio do controle de constitucionalidade, frequentemente os princípios são invocados na adaptação e atualização do ordenamento, sob o argumento de comportarem situações diversificadas e, principalmente, por nunca se afastarem completamente de sua validade, independentemente do contexto a que são expostos. Muitos autores já atribuem aos princípios a

\footnotetext{
${ }^{1}$ Pós-Graduando em Teoria Direito (mestrado) pela Pontifícia Universidade Católica de Minas Gerais. Membro pesquisador do Grupo de Pesquisa Investigação Científica Constituição e Processo. Membro estudante do Grupo de pesquisa Direito e razão prática. E-mail: andrenelvam@hotmail.com
} 
harmonização do ordenamento, contudo, sem apresentar uma relação direta com sua estrutura normativa de aplicação.

A primeira parte do presente trabalho tem como caminho a contextualização histórica, perpassando pelas principais teorias, levando o escopo, por meio de uma abertura reflexiva do esclarecimento da relevância da tipologia normativa dos princípios sobre a jurisdição constitucionalizada, focando-se no impacto que aquela exerce sobre esta.

Em seguida serão abordadas teorias voltadas ao esclarecimento da compreensão como forma de concretização do direito, através da distinção entre norma e texto normativo e da exploração dos principais aspectos da ontologia heideggeriana como forma de compreensão. O seu estudo tem como escopo a clarificação da interpretação como fator determinante da concretização, além dos elementos contidos no texto normativo e no contexto fático-material em que ocorre.

Por fim, apresentado o resultado da problematização da proposta sobre a divisão das normas em duas espécies, princípios e regras, muitos pontos mostram-se controversos acerca da normatividade dos princípios e sua influência sobre a constitucionalização do direito como unidade de ordenamento. Dentre eles, a ideia de que a bipolarização normativa necessariamente admite a coexistência de dois modelos de aplicação a partir de um mesmo conjunto textual à escolha do aplicador, sendo o primeiro positivista (regras), pautado na presunção de correção pela mera subsunção e um modelo aberto (princípios), no qual a argumentação fundamenta a normatividade.

\section{PRINCÍPIOS E REGRAS COMO ESPÉCIES DO GÊNERO NORMA}

A doutrina, ao classificar as normas constitucionais com base na estrutura normativo-material ${ }^{2}$, guiada pela necessidade de uma "dogmática de clarificação tipológica da estrutura normativa"3 divide o gênero norma em duas espécies distintas: princípios e regras, consolidando a afirmação de que ambos expressam conteúdo deôntico. "Há consenso na dogmática jurídica contemporânea de que princípios e regras desfrutam igualmente do status de norma jurídica, distinguindo-se uns dos outros por critérios variados." (BARROSO, 2009, p.317).

Contudo, a distância entre os critérios de diferenciação, muitos deles insuficientes para uma separação consistente, bem como a indefinição contextual de cada uma das abordagens propostas, torna o tema confuso, mantendo-os afastados entre si, comprometendo sua colaboração científica para a prática interpretativa constitucional. Alguns exemplos mostram o caminho até então trilhado. Luiz Roberto Barroso propõe uma divisão simplificadamente resumida em três critérios:

\footnotetext{
${ }^{2}$ MENDES, Gilmar Ferreira, (2009, p.52)

${ }^{3}$ CANOTILHO, José Joaquim Goemes. 2002, p. 1143.
} 
1. Quanto ao conteúdo: regras são relatos objetivos descritivos de condutas a serem seguidas; princípios expressam valores ou fins a serem alcançados;

2. Quanto à estrutura normativa: regras se estruturam, normalmente, no modelo tradicional das normas de conduta: previsão de um fato - atribuição de um efeito jurídico; princípios indicam estados ideais e comportam a realização por meio de variadas condutas;

3. Quanto ao modo de aplicação: regras operam por via do enquadramento do fato no relato normativo, com enunciação da consequência daí resultante, isto é, aplicam-se mediante subsunção; princípios podem entrar em rota de colisão com outros princípios ou encontrar resistência por parte da realidade fática, hipóteses em que serão aplicados mediante ponderação. (BARROSO, 2009, p.317).

A abordagem supra é interessante, pois se relaciona, mesmo que indiretamente, com as teorias que tratam o direito como relação intersubjetiva qualificada normativamente (BOBBIO, 1993, pp. 42 a 44). Há na relação jurídica papel fundamental para a determinação da espécie normativa, o que traz ao olhar a aptidão da norma a regular relações previamente (ou não) determinadas, como medida de aproximação da realidade. Assim, a conduta figura o objeto principal da regra, diferenciando-a dos princípios nos três modos propostos. José Joaquim Gomes Canotilho elenca os seguintes critérios:

1. Grau de abstracção: os princípios são normas com um grau de abstracção relativamente elevado; de modo diverso, as regras possuem uma abstracção relativamente reduzida.

2. Grau de determinabilidade na aplicação do caso concreto: os princípios, por serem vagos e indeterminados, carecem de mediações concretizadoras (do legislador, do juiz), enquanto as regras são susceptíveis de aplicação directa.

3. Caráter de fundamentalidade no sistema das fontes de direito: os princípios são normas de natureza estruturante ou com um papel fundamental no ordenamento jurídico devido à sua posição hierárquica no sistema das fontes (ex:: princípios constitucionais) ou à sua importância estruturante dentro do sistema jurídico (ex.: princípio do Estado de Direito).

4. "Proximidade" da idéia de direito: os princípios são "standards" juridicamente vinculantes radicados nas exigências de "justiça" (Dworkin) ou na "ideia de direito" (Larenz); as regras podem ser normas vinculativas com um conteúdo meramente funcional.

5. Natureza normogenética: os princípios são fundamento das regras, isto é, são normas que estão na base ou constituem a ratio de regras jurídicas, desempenhando, por isso, uma função normogenética fundamentante. (CANOTILHO, 2002, pp. 1144 e 1145).

O autor português destaca a necessidade de se diferenciar os princípios hermenêuticos dos princípios jurídicos, em razão de potencial dúvida quanto às funções desempenhadas pelos princípios. Os primeiros desempenham função retórico-argumentativa (cânones de interpretação), utilizados no desenvolvimento, integração e complementação do direito. Portanto, de acordo com seu pensamento, não são normas, não 
figurando, por consequência, objeto do presente trabalho. Somente os segundos, princípios jurídicos, é que carregam tal qualidade.

A partir da análise, centrada nas teses que tratam das diferenças qualitativas entre princípios e regras, na esteira de Dworkin e Alexy, como se verá adiante, o autor português defende que a existência de princípios e regras permite a descodificação da estrutura sistêmica, ou seja, a "compreensão da constituição como sistema aberto de regras e princípios." (CANOTILHO, 2002, pp. 1145 e 1146, grifos originais).

Jorge Miranda atribui aos princípios a coerência e consistência do ordenamento, composto por normas. "E esse ordenamento, esse conjunto, essa unidade, esse valor projecta-se ou traduz-se em princípios, logicamente anteriores aos preceitos." (MIRANDA, 2007, p.431). De acordo com o autor, são características dos princípios:

1. A sua maior aproximação da idéia de Direito ou dos valores do ordenamento;

2. A sua amplitude, o seu grau de maior generalidade ou indeterminação frente às normas-regras;

3. A sua irradiação ou projecção para um número vasto de regras ou preceitos, correspondentes a hipóteses de sensível heterogeneidade;

4. A sua versatilidade, a sua susceptibilidade de conteúdos algo variáveis ao longo dos tempos e das circunstâncias, com densificações variáveis;

5. A sua abertura, sem pretensão de regulamentação exaustiva, ou em plenitude, de todos os casos;

6. A sua expansibilidade perante situações ou factos novos, sem os absorver ou neles se esgotar;

7. A sua virtualidade de harmonização, sem revogação ou invalidação recíproca. (MIRANDA, 2007, p.433).

A partir das diferenciações propostas, os professores portugueses passam a subdividir princípios em tipos e categorias, com base em seu conteúdo, função ou mesmo em seu grau de abstração. Tais classificações fogem ao objeto do presente trabalho, que se limita apenas à distinção entre as espécies normativas princípios e regras.

Seguindo a linha de distinção entre postulados normativos e normas de primeiro grau, sendo estas constituídas por princípios e regras, Humberto Ávila persegue maior exatidão na definição e utilização do conceito de princípios. Em sua obra intitulada Teoria Geral dos Princípios, analisa a dissociação entre princípios-norma e regras valendo-se da separação entre normas de primeiro grau (princípios e regras) e postulados normativos aplicativos ou metanormas (normas de segundo grau):

Os postulados normativos aplicativos são normas imediatemente metódicas que instituem os critérios de aplicação de outras normas situadas no plano do objeto da aplicação. (...). Os postulados funcionam diferentemente dos princípios e das regras. A uma, porque não se situam no mesmo nível: os princípios e as regras são normas objeto da aplicação; os postulados são normas que orientam a aplicação de outras. A duas, porque não possuem os mesmos destinatários: os princípios e regras são primariamente dirigidos ao Poder Público e aos contribuintes; os postulados são frontalmente dirigidos ao intérprete e aplicador do Direito. A três, porque não se relacionam da 
mesma forma com outras normas: os princípios e as regras (...) implicam-se reciprocamente, quer de modo preliminarmente complementar (princípios), quer de modo preliminarmente decisivo (regras). (ÁVILA, 2012, p. 142).

Segundo o autor, a doutrina apresenta três critérios de distinção entre as espécies de norma. O primeiro centra-se no "caráter hipotético-condicional", pois, para alguns doutrinadores:

As regras possuem uma hipótese e uma consequência que predeterminam a decisão, sendo aplicadas ao modo se, então; os princípios apenas indicam o fundamento a ser utilizado pelo aplicador para, futuramente, encontrar a regra aplicada ao caso concreto. (ÁVILA, 2012, p. 43).

Trata-se de critério focado no aspecto estrutural do dispositivo do qual se deriva a norma, pressupondo a preexistência dos elementos hipótese e consequência normativa no texto legislativo para o caso de regras, enquanto no dos princípios não.

Em análise crítica, afirma ser esse um critério frágil por sua imprecisão com relação às ideias de que princípios seriam o primeiro passo de obtenção da regra, enquanto as regras, sejam positivadas ou obtidas, o último passo. Pois o "último passo não é dado pelo dispositivo nem pelo significado preliminar da norma, mas pela decisão interpretativa (...). " Outra crítica reside no fato de que a "existência de uma hipótese de incidência é questão de formulação linguística e, por isso, não pode ser elemento de distintivo de uma espécie normativa." (ÁVILA, 2012, p. 44).

O segundo critério está no "modo final de aplicação", sob o qual se afirma que "as regras são aplicadas no modo absoluto tudo ou nada, ao passo que os princípios, de modo gradual mais ou menos." São expoentes dessa doutrina tanto Dworkin quanto Alexy. De acordo com o autor, a crítica repousa no fato das regras nem sempre possuírem tal carater absoluto, podendo ser aplicadas gradativamente (ÁVILA, 2012, pp.48 a 55).

Por fim, o terceiro critério encontra-se no caso de "conflito normativo", pois para alguns autores "a antinomia entre regras consubstancia verdadeiro conflito, (...) ao passo que o relacionamento entre os princípios consiste num imbricamento, a ser decidido mediante uma ponderação que atribui uma dimensão de peso a cada um deles." (ÁVILA, 2012, p. 56). Considerando tal critério é observado que, não obstante ser um "passo decisivo no aprimoramento" da matéria, ainda merece aperfeiçoamento, pois há casos de ponderação de regras, por razões como a presença de elementos semanticamente abertos, generalizações, utilização de analogia, entre outras. (ÁVILA, 2012, pp. 57 e seguintes).

A partir das reflexões sobre os modelos estudados, empenha-se o autor na sua superação ou aperfeiçoamento, tomando como alicerce a construção da norma pelo intérprete "a partir dos dispositivos e do seu significado usual." Valoriza, portanto, independência entre o texto legal e as "conexões axiológicas", elementos dos quais surge a norma, gerando uma dissociação que se desdobra do caráter pluridimensional dos enunciados normativos. 
Por isso a distinção entre princípios e regras deixa de se construir em uma distinção quer com valor empírico, sustentado pelo próprio objeto da interpretação, quer com valor conclusivo, não permitindo antecipar por completo a significação normativa e seu modo de obtenção. (...) funciona como modelo ou hipótese provisória de trabalho para uma posterior reconstrução de conteúdos normativos, sem, no entanto, assegurar qualquer procedimento estritamente dedutivo de fundamentação ou de decisão a respeito desses conteúdos. (ÁVILA, 2012, p.75).

Ressalta-se que a proposta encontra feição ímpar por admitir a coexistência das espécies normativas em um mesmo dispositivo legal, de modo que passam elas a diferenciar-se "quanto ao dever que instituem, à justificação que exigem e ao modo como contribuem para solucionar conflitos." (ÁVILA, 2012, p. 77).

Sobre o dever que instituem, as regras têm como dever imediato a adoção da conduta descrita, enquanto os princípios têm como dever imediato a promoção de um estado ideal de coisas. Por conseguinte, dever mediato das regras é a manutenção de fidelidade à finalidade subjacente e aos princípios superiores, tendo em vista que a conduta descrita em uma regra não pode deixar de buscar o atingimento do estado ideal imediatamente devido pelos princípios. Lado outro, os princípios têm como dever mediato a adoção da conduta necessária.

Quando a justificação é o critério de dissociação, os princípios extraem a fundamentação dos seus efeitos na correlação entre efeitos da conduta e o estado ideal das coisas, enquanto as regras da correspondência entre o conceito da norma e o conceito do fato.

Por fim, sobre o critério de dissociação baseado na pretensão de decidibilidade de cada espécie normativa, tem-se que os princípios possuem uma pretensão de complementaridade e parcialidade, pois não visam "gerar uma solução específica, mas de contribuir, ao lado de outras razões para a tomada de decisão. ” Já as regras, por sua vez, possuem "pretensão terminativa, na medida em que, sobre pretenderem abranger todos os aspectos relevantes para a tomada de decisão, têm a pretensão de gerar uma solução específica para a questão." Tentam, em certa medida, antecipar descritivamente o fato que gerará sua incidência, sob o manto da exclusividade e abarcância (ÁVILA, 2012, p. 84).

Como visto, a doutrina trabalha com subdivisões das espécies normativas, a exemplo dos autores portugueses, que classificam os princípios de diversas maneiras. Também a nomenclatura princípios é utilizada para uma categoria internormativa, como os princípios de interpretação de Canotilho. Há também os postulados normativos do professor Humberto Ávila, ao lado das normas subdivididas em princípios e regras.

Contudo, a classificação interna dos princípios-norma não figura objeto do presente trabalho, que se concentra apenas em sua normatividade, com o fito de esclarecer a relação entre princípios constitucionais e regras jurídicas na harmonização do direito infraconstitucional à Constituição por meio da interpretação e aplicação. Tampouco serão considerados os demais tipos de enunciados carentes de normatividade, ou de normatividade indireta, como os postulados. Como decorrência do recorte, passa-se a tratar tão somente dos 
princípios-norma, insertos nas constituições, cuja normatividade recai sobre o destinatário final da norma, excluindo-se da analise os chamados princípios hermenêuticos.

\section{A NORMATIVIDADE DOS PRINCIPIOS}

Compreende-se a importância do tema quando pensamos os princípios como Constituição e, portanto, hierarquicamente superiores a todo o ordenamento dela decorrente e nela legitimado. Nos dizeres de Paulo Bonavides, "Os princípios, uma vez constitucionalizados, se fazem a chave de todo um sistema normativo." (BONAVIDES, 2008, p.258). E prossegue em seu ensinamento:

A inserção constitucional dos princípios ultrapassa, de último, a fase hermenêutica das chamadas normas programáticas. Eles operam nos textos constitucionais na segunda metade deste século $(\mathrm{XX})$ uma revolução de juridicidade sem precedente nos anais do constitucionalismo. De princípios gerais se transformaram, já, em princípios constitucionais. (...) Todo o discurso normativo tem que se colocar, portanto, em seu raio de abrangência os princípios, aos quais as regras se vinculam. (BONAVIDES, 2008, p.259).

A principiologia constitucional hodierna aparece como o apontamento de um caminho de superação das limitações do positivismo, descortinando novos conceitos, não só o de princípios, mas também o de regras e normas de uma forma geral. Ao levantar questões sobre a certeza do direito em sua aplicação, principalmente no que tange a limitações impostas ao aplicador, Bernardo Gonçalves Fernandes esclarece que a correta compreensão das teorias da hermenêutica jurídica, para vários juristas, tem como pressuposto a compreensão da distinção entre princípios e regras dada pela ciência jurídica:

A questão para importantes teóricos pós-positivistas (que buscam superar o positivismo e o seu modelo de ordenamento jurídico, bem como de hermenêutica) é: qual a certeza que podemos ter do direito e de sua aplicação? Quem pode limitar o aplicador? (...)

Vários juristas vão pôr em relevo a construção de um ordenamento jurídico com base não só em regras, mas também em princípios jurídicos. Essa perspectiva vai ter como objetivo central superar a concepção positivista atrelada a um sistema jurídico fechado, preso em um modelo de regras. (FERNANDES, 2010, pp. 185 e 186, grifos originais).

A transição hermenêutica dos princípios da condição de princípios gerais do Direito para a condição de princípios constitucionais é marcada essencialmente pelo reconhecimento da sua normatividade, tornando-os, assim como as regras, uma nova espécie do gênero norma. Passa a existir uma exigência de concretização sobre o aplicador que deve, em respeito à sua posição hierárquica superior de texto constitucional, encontrar maneiras de expressar seu conteúdo deôntico em face da realidade, direcionando a interpretação das normas infraconstitucionais. Sobre o desenrolar histórico, Paulo Bonavides: 
As Constituições fazem no século XX o que os Códigos fizeram no século XIX: uma espécie de positivação do Direito Natural, não pela via racionalizadora da lei, enquanto expressão da vontade geral, mas por meio dos princípios gerais, incorporados na ordem jurídica constitucional, onde logram valoração normativa suprema, adquirem a qualidade de instância juspublicística primária, sede de toda a legitimidade do poder. Isto, por ser tal instância a mais consensual de todas as intermediações doutrinárias entre o Estado e a Sociedade. (BONAVIDES, 2008, p.293)

Sendo assim, como a inserção dos princípios gerais do direito nas constituições contribuiu decisivamente para a consolidação da sua normatividade, certo é que a relação entre princípios constitucionais e regras de direito infraconstitucionais será constituída por uma interpretação em que os princípios inevitavelmente vincularão a atividade do aplicador, mesmo que em detrimento dos efeitos prescritos nas regras envolvidas.

A consequência jurídica do princípio, tida expressão do seu caráter deôntico, em um primeiro olhar, tem o condão de afastar a regra infraconstitucional do caso concreto, mesmo que esta tenha em sua hipótese descritiva fato jurígeno semelhante ao fato concreto que lhe foi confrontado. Por exemplo: Se após exercício contextualização ${ }^{4}$, a aplicação da regra infraconstitucional não sustentar como pressuposto a situação exigida por algum dos princípios constitucionais, ao arrepio do seu conteúdo, deverá então ser afastada daquele caso concreto.

\section{O CAMINHO DA CONQUISTA DA NORMATIVIDADE DOS PRINCÍPIOS}

A distinção entre as concepções sob as quais os princípios são tratados informará de maneira mais organizada as características compatíveis com a sua normatividade, a partir da contextualização no caminho doutrinário, descortinando os pontos fundamentais de diferenciação entre as duas espécies normativas.

\section{Concepções jusnaturalista e positivista}

Os princípios passaram por momentos históricos muito distintos em que sua natureza, estrutura e aplicação, revelavam-se a partir de concepções específicas. Paulo Bonavides, em trabalho de síntese, distingue três concepções como marcos da caminhada rumo à conquista da sua normatividade.

A primeira delas consiste na concepção jusnaturalista, caracterizada pela predominante abstratividade, funcionando os princípios como referenciais éticos universais de justiça e do bem obrar. São extraídos não só do ordenamento, quando também do Direito Natural, com claro escopo de se atingirem ideais de justiça. "Os princípios habitam ainda esfera por inteiro abstrata e sua normatividade, basicamente nula e duvidosa, contrasta

\footnotetext{
${ }^{4} \mathrm{O}$ presente trabalho não aprofunda no "exercício de contextualização", expressão ampla demais para ser abordada corretamente aqui. Contudo, cabe ressaltar que é possível entender nesta um ponto fundamental de compreensão da atividade interpretativa, pois é justamente no "exercício de contextualização" que se inserem os elementos da norma.
} 
com o reconhecimento de sua dimensão ético-valorativa de ideia que inspira os postulados de justiça. " (BONAVIDES, 2008, p. 259).

Cabe por bem ressaltar que a concepção jusnaturalista, a mais antiga teoria a conceituar princípios, diante da "presença marcante das ideias filosóficas e políticas que firmaram o Estado Liberal", considerava princípios como a "expressão desses novos valores, possuindo, pois, um peso fortemente ético e não jurídico." Outro ponto importante do jusnaturalismo gravita em torno da fonte dos princípios, que deduzidos pela reta razão, agiam como "verdadeiros axiomas jurídicos", carentes, devido ao nível abstrato em que pairavam, de juridicidade. (PEREIRA, 2001, p.128).

A concepção seguinte é a positivista que, por alocar os princípios nos Códigos ao lado das demais normas, "representa uma etapa intermediária" na afirmação da sua juridicidade. São extraídos do próprio ordenamento, como generalizações das próprias normas positivadas e não do Direito Natural "e, por isso, não podem ser considerados, como antes, instância supralegal". Os denominados princípios gerais do direito têm uma função interpretativa subsidiária, ou seja, são considerados apenas para o preenchimento de lacunas existentes no próprio ordenamento de regras, impedindo assim o "vazio normativo". Por conseguinte, podemos entender que a concepção positivista ainda aloca os princípios no mais baixo nível hierárquico de normas. Em conclusão:

Podemos dizer que a diferença mais destacada entre a tendência histórica e positivista e a jusnaturalista radica em que esta última afirma a insuficiência dos princípios extraídos do próprio ordenamento jurídico positivo, para preencher as lacunas da lei, e a necessidade consequente de recorrer aos do Direito Natural (demais, com todas as garantias que temos visto), enquanto que a corrente positivista entende que se pode manter dentro do ordenamento jurídico estatal, com os princípios que deste se podem obter por analogia. (PANIGUA, 1976, pp. 125 e 126 apud BONAVIDES, 2008, p.262).

Repise-se: de acordo com BONAVIDES (2008), com a inserção dos princípios nas Constituições, ocorrida principalmente após as grandes guerras do século XX, estes deixam de ser entendidos como valores abstratos ou fonte interpretativa subsidiária, passando a ser considerados como normas tanto quanto as regras jurídicas.

Quando se invoca as classificações doutrinárias acerca das características e diferenças dos princípios em face das regras, nota-se que aquelas fundadas em seu conteúdo são eminentemente jusnaturalistas, enquanto as que versam sobre sua estrutura normativa terão amparo na concepção positivista ora exposta, por presas unicamente ao referencial linguístico dos enunciados. Isso fica bem claro na divisão proposta por Luís Roberto Barroso, transcrita anteriormente, sendo possível um paralelo entre os três critérios de diferenciação enumerados pelo autor e as três concepções assinaladas por Paulo Bonavides.

No caso dos autores portugueses, não obstante a proposta de um número maior de critérios de diferenciação (CANOTILHO, 2002, pp. 1144 e 1145), ou de características dos princípios (MIRANDA, 2007, 
p.433), acredita-se ser possível agrupá-los sob os três critérios básicos, quais sejam, pelo conteúdo, estrutura normativa e modo de aplicação.

Como a normatividade dos princípios é o foco do presente trabalho, considerar-se-á apenas as características inerentes à concepção pós-positivista, porquanto ser a mais próxima a sustentar de forma satisfatória o caráter deôntico das normas-princípios insertas nas constituições hodiernas.

De toda forma, cabe verificar alguns aspectos hermenêuticos da última concepção, associada à inserção da interpretação princípio lógica na aplicação do texto constitucional. Isso porque a inserção dos princípios nas constituições não ocorre apenas na dimensão do texto, sendo fundamental para sua efetividade a alteração também dos métodos de construção das normas pelos órgãos de aplicação.

\section{A concepção pós-positivista e as teses qualitativas de diferenciação}

A transformação dos princípios gerais do direito, inseridos nos Códigos, para princípios constitucionais, foi o passo mais importante para o afloramento de sua normatividade, "marcando o tratamento juspuplicista destes por oposição ao tratamento jusprivatista típico da fase positivista”. Considerando essa juridicidade dos princípios, o pós-positivismo conta com duas fases distintas:

1. Fase programática: em que possuem aplicabilidade diferida e, portanto, normatividade mínima, eis que são vistos como programas normativos a serem concretizados aos poucos pelos operadores jurídicos, e

2. Fase não programática: em que há reversão do conceito, pelo que os princípios passam a ser considerados em sua dimensão objetiva e concretizadora, tendo, pois, aplicação direta e imediata. (PEREIRA, 2001, p.129).

O enfrentamento da questão encontra seu nascimento na necessidade de realização das obrigações provenientes dos princípios como espécie norma, sendo, portanto, os princípios, emanadores de direitos e deveres realizáveis de imediato, por meio da jurisdição. Apesar das diferenças estruturais, tornou-se fundamental a atribuição de elementos deônticos aos princípios, por se tratarem de texto constitucional.

A reação pós-positivista ganha força com as teorias de Ronald Dworkin e Robert Alexy, pois, apesar de diferenciadas em suas propostas e contextos, partem da aplicabilidade dos princípios e regras como critério mais importante em sua distinção. Sendo assim, como aponta Alexy, as teses focadas na generalidade dos princípios, p. ex, são teses fracas ${ }^{5}$ para a diferenciação, "uma vez que apoiam em uma distinção meramente quantitativa" (FERNANDES, p. 186). Em outros termos:

\footnotetext{
${ }^{5}$ Como colocado no item 2 do presente trabalho, ainda são utilizados pela doutrina critérios de diferenciação provenientes da concepção jusnaturalista, como as que focam em seu conteúdo, bem como positivista, que tratam das diferenças meramente estruturais.
} 
Ambos vão sustentar uma forte distinção entre essas espécies normativas não mais baseada em tal critério de generalidade, mas em virtude de sua aplicabilidade. Ou seja, regras e princípios são aplicáveis às situações concretas de maneiras distintas. (PEREIRA, 2001, p.142).

Há, portanto, uma ampliação do conceito de norma, gerada pela diferenciação qualitativa, por esta se voltar à sua aplicabilidade. Inevitavelmente insere-se na construção da norma a função jurisdicional, trazendo às mãos do aplicador função de (re) criação da própria norma como parte de um ordenamento contextualizado. Ao propor a chamada "lei de colisão" Robert Alexy vincula à precedência de um princípio sobre o outro uma condição, dada no caso concreto. Quando trata da ponderação (sopesamento) entre princípios colidentes feita pelo Tribunal Constitucional Federal alemão, explica que:

É necessário indagar o que se quer dizer quando se fala em "pesos". O conceito de relação condicionada de precedência oferece uma resposta simples. Em um caso concreto, o princípio P1 tem um peso maior que o princípio colidente $\mathrm{P} 2 \mathrm{sob}$ as condições $\mathrm{C}$, presentes nesse caso concreto. (...). As condições sob as quais um princípio tem precedência em face de outro constituem suporte fático de uma regra que expressa a consequência jurídica do princípio que tem precedência.

Essa lei, que será chamada de "lei de colisão", (...) reflete a natureza dos princípios como mandados de otimização: em primeiro lugar, a inexistência de relação absoluta de precedência e, em segundo lugar, sua referência a ações e situações que não são quantificáveis. (ALEXY, 2008, pp. 97 e 99).

A norma só é, então, sob sua perspectiva dinâmica. Se para a aplicação é necessário que se pense o caso concreto e nos efeitos nele gerados, ou mesmo nas condições de precedência de um princípio sobre outro, conclui-se que a sua estruturação, necessariamente, deverá contar com elementos fáticos, característicos caso específico confrontado com as redações legislativas aplicadas.

Tal visão pautada na dinâmica de aplicação como forma de determinação do tipo normativo corrobora com a distinção entre norma e texto normativo. Quando se pensa os princípios e as regras por meio da aplicabilidade, admite-se a hipótese de um mesmo texto abrigar um princípio ou uma regra, a ser apurado por seu modo de aplicação. Fica muito clara essa afirmação quando se trata do texto normativo que expressa direitos fundamentais.

Nesse sentido, mesmo que todas as normas de direitos fundamentais diretamente estabelecidas tivessem a estrutura de princípios - o que, como ainda se demonstrará, não ocorre -, ainda assim haveria normas de direitos fundamentais com a estrutura de princípios e normas de direitos fundamentais com a estrutura de regras. (ALEXY, 2007, p.102).

Um direito fundamental, p. ex., se é aplicado diretamente, do modo tudo ou nada, por meio de uma relação jurídica extraída diretamente do seu texto, será uma regra. Se o mesmo passa por uma aplicação na maior medida possível, muitas vezes irradiando-se sobre outras normas, será então um princípio.

\section{Características dos princípios sob a concepção pós-positivista}


O primeiro ponto das teses qualitativas de determinação das espécies normativas encontra-se, como aponta Dworkin, no fato de que as regras têm uma aplicação claramente definida, não permitindo gradações em sua realização como direito. Uma obrigação proveniente de uma regra deve ser aplicada ou não, no modelo tudo ou nada, sendo apta a surtir efeitos na realidade da forma em que foi estruturada ou, ao contrário, totalmente inadequada, devendo ser inteiramente afastada. Já os princípios, diferentemente, permitem sua aplicação na maior medida possível, não sendo totalmente afastados em casos de colisão.

As diferenças qualitativas traduzir-se-ão, fundamentalmente, nos seguintes aspectos. Os princípios são normas jurídicas impositivas de uma optimização (...); as regras são normas que prescrevem imperativamente uma exigência (...). A convivência entre princípios é conflitual (Zagrebelsky), a convivência de regras é antinómica; os princípios coexistem, as regras antinómicas excluem-se. (CANOTILHO, 2002, p.1145).

As teses qualitativas, ao deslocarem a conceituação dos tipos normativos para o momento de sua aplicabilidade, inserem no conceito de norma a maneira como esta se aproxima da realidade, ultrapassando os limites da lógica formal impostos pela análise abstrata dos preceitos legislativos. Dessa forma:

Pode-se dizer que os princípios jurídicos se produzem necessariamente em dois tempos e a quatro mãos: primeiro são formulados genérica e abstratamente pelo legislador; depois se concretizam, naturalmente, como normas do caso ou normas de decisão pelos intérpretes e aplicadores do Direito. (MENDES, 2009, p. 56).

Sem adentrar nas diferenças entre as propostas da integridade do direito, de Dworkin, e a técnica da lei de colisão, de Alexy, esta utilizada na jurisdição alemã, de onde decorre a ponderação e a proporcionalidade, muito difundidas na jurisdição pátria ${ }^{6}$, por fugir do tema do presente trabalho, pode-se mesmo assim afirmar com segurança, diante do exposto, que o contato da norma com as hipóteses fáticas apresenta os fatores determinantes da estrutura daquela (norma) e dos reflexos produzidos na realidade.

Uma característica decorrente da aplicabilidade dos princípios é justamente a capacidade de adaptação dessa espécie normativa a um número maior de situações fáticas, em decorrência do fato de serem inarredáveis. Os princípios não se anulam em casos de conflito, pois devem irradiar sobre todo o ordenamento em todas as situações. É o que se encontra no que Jorge Miranda coloca como "expansibilidade perante situações ou factos novos, sem os absorver ou neles se esgotar" (MIRANDA, 2007, p.433).

Trata-se, pois, de esclarecer se há relevância no fato da relação juridicamente qualificada não se encontrar claramente definida nos enunciados dos princípios-norma, e se isso em geral ocorre com as regras. Se o enunciado

\footnotetext{
${ }^{6}$ FERNANDES, Bernardo Gonçalves. Curso de Direito Constitucional - Rio de Janeiro: Lumen Iuris, 2010. Para Dworkin, os princípios apresentam, em face das regras, "distinção lógico-argumentativa" e "não em razão de sua estrutura de aplicação ou por características morfológicas” (p. 198). Já Alexy, "separa princípios e regras por meio de critérios morfológico-estruturais, ou seja, as condições de aplicação se dão de maneira prévia à situação real e concreta de aplicação, de modo que é possível, nessa perspectiva teórica, analisar uma norma em abstrato e ter segurança de estarmos diante de um princípio ou de uma regra.” (p.190). Enquanto Alexy retorna à análise formal, Dworkin atrela a norma ao caso concreto e seus elementos argumentativos.
} vol.08, nº. 03, Rio de Janeiro, 2015.pp. 1244-1270 
exerce tal papel na diferenciação das espécies, os princípios se caracterizariam por não se limitarem a um número determinado de hipóteses. Assim, parte do papel do aplicador seria exprimir a adequação de um fato ao conteúdo de um princípio naquele caso concreto, não esgotando as possibilidades de outros fatos sofrerem a intervenção princípio lógica.

Atrelando-se a norma ao enunciado, a abertura textual dos princípios constitucionais, destarte, seria responsável por comportamento de um número maior de fatos na projeção dos seus efeitos, tendo-se em vista constituírem-se como fundamentos de todo o ordenamento. Afinal, a aplicação de toda regra infraconstitucional imprescinde da consonância com o conteúdo dos princípios constitucionais.

Neste ponto, nos estudos de CANOTILHO, a constituição como um sistema aberto de regras e princípios se daria a partir dessa dinâmica entre generalidade dos princípios e a realização das regras. A indefinição prescritiva dos princípios, principalmente no que tange à prescrição de fato ou conduta, levaria às mãos do aplicador a aferição de quais relações exigem a intervenção interpretativa conformadora da realidade em face do seu conteúdo.

Fica claro que para conceber a abertura interpretativa da Constituição como decorrência da generalidade dos princípios é imprescindível aceitar que a sinonímia entre norma e enunciado. Somente assim seria possível dizer que os enunciados das regras possuem maior previsibilidade contingencial pragmática do que os enunciados dos princípios, disso decorrendo a abertura constitucional pela inserção dos princípios no seu corpo textual.

Porém, a questão se demonstra mais complexa do que a mera aplicação que tem um enunciado como ponto de partida para o provimento jurisdicional final. Se a diferenciação entre princípios e regras ocorre de forma qualitativa, como nos ensina a reação pós-positivista, necessária é a dissociação entre os conceitos de norma e enunciado normativo. Afinal, se não é possível distinguir um princípio de uma regra, isso somente ocorre porque o texto legal não carrega elementos suficientes para tanto, apesar de impor certas significações prévias balizadoras da aplicação.

Assim, a abertura do conteúdo constitucional e sua influência sobre a aplicação das demais normas não pode ser encarada a partir dos enunciados textuais e seus elementos. Porém, isso não descarta a compreensão dos princípios-norma como fator importante no redimensionamento da constitucionalização do direito, que deve ser trabalhada sob outra perspectiva, das suas peculiaridades na hermenêutica de aplicação.

\section{NORMATIVIDADE: TEXTO, MATERIALIDADE E INTERPRETAÇÃO}

\section{A questão da generalidade do texto normativo}

O tratamento constitucional dos princípios, de acordo com o exposto, leva ao entendimento de que o aplicador, diante das diferenças hierárquicas entre as normas, passou a adaptar-se à textura aberta do texto criando 
novas alternativas de aplicação. Porém, apenas a superioridade hierárquica do texto constitucional não se mostra de forma convincente como fator único, ou mesmo primordial, para a aquisição de normatividade pelos princípios. Isso porque as normas estão ligadas, mas não presas aos enunciados legais.

A influência do texto na construção normativa não tem o condão de esclarecer de antemão qual espécie normativa será construída. Logo, o texto constitucional não dirá sobre princípios especificamente, carecendo de interpretação para tanto. Como exemplo, a textura aberta do texto será insuficiente para a distinção prévia entre as espécies normativas.

O caráter aberto do texto normativo de uma forma geral, independente da classificação das duas espécies, princípios e regras, tem apontado para uma gradação e não especificamente uma cisão bipolarizada. Isso quer dizer que, diante da divisão entre princípios e regras, as regras também possuem graus diferentes de abertura textual, bem como os próprios princípios carregam graus diferentes de especificidade.

Hart aponta com clareza que todas as normas carregam um grau, elevado ou não, de abstração, deixando margem contingente para a aplicação diante da realidade fática.

Seja qual for o processo escolhido, precedente ou legislação, para a comunicação de padrões de comportamento, estes, não obstante a facilidade com que actuam sobre a grande massa de casos correntes revelarse-ão como indeterminados em certo ponto em que sua aplicação esteja em questão; possuirão aquilo que foi designado como textura aberta. (HART, 2001, p. 140 e 141).

$\mathrm{O}$ autor atribui o caráter aberto dos textos normativos à própria na natureza humana marcada pela incapacidade de apreender por meio da linguagem a complexidade das relações futuras. Nisso critica o formalismo por insistir na tentativa de exatidão pela cobertura das possibilidades pelo texto, negligenciando a incapacidade humana de previsão do futuro.

De facto, todos os sistemas, de formas diferentes, chegam a um compromisso entre duas necessidades sociais: a necessidade de certas regras que podem, sobre grandes zonas de conduta, ser aplicadas com segurança por indivíduos privados a eles próprios, sem uma orientação oficial nova ou sem ponderar as questões sociais, e a necessidade de deixar em aberto, para a resolução ulterior através de uma escolha oficial e informada, questões que só podem ser adequadamente apreciadas e resolvidas quando surgem num caso concreto. (HART, 2001, p. 143).

Disso decorre a necessidade da gradativa especificidade entre as inúmeras normas de um sistema, sendo algumas de interpretação mais definida contextualmente enquanto outras exigem um trabalho mais intenso da autoridade aplicadora, diante das circunstâncias fáticas:

A textura aberta do direito significa que há, na verdade, áreas de conduta em que muitas coisas devem ser deixadas para serem desenvolvidas pelos tribunais ou pelos funcionários, os quais determinam o equilibrio, à luz das circunstâncias, entre interesses conflitantes que variam em peso, de caso para caso. (HART, 2001, p. 148). 
Hans Kelsen ao diferenciar normas gerais de normas individuais apontava para a função das primeiras como o sentido do dever-se, sem aplicabilidade direta no caso concreto. Ao desenvolver sobre a insuficiência da lógica formal no tratamento dos enunciados textuais, em razão do texto normativo não ter natureza apofântica, acaba por atribuir a obrigatoriedade à norma individual formulada diante do caso concreto:

Que uma norma 'vale' significa então que ela deve ser cumprida e aplicada, e apenas pode ser imediatamente cumprida e aplicada a uma norma individual categórica, mas só mediatamente uma norma geral hipotética, então uma norma geral hipotética só pode valer mediatamente: intervém mediante a validade da norma individual categórica que lhe corresponde, na qual é posta como devida in concreto a conduta fixada in abstracto na norma geral hipotética. Isso pressupõe o reconhecimento da norma geral hipotética pelo indivíduo que estabelece a norma individual categórica. Contanto precise ser aderida à frequentemente defendida Teoria do Reconhecimento, conforme a qual a validade de uma ordem moral ou jurídica depende de seu reconhecimento pelos indivíduos subordinados à ordem. (KELSEN, p. 62).

Inobstante Hans Kelsen não considere como um dos elementos da norma o âmbito fático de aplicação, deixando margem para o arbítrio do julgador, seu pensamento já indica a diferença entre norma e enunciado normativo, expondo que a incompletude diante da realidade é uma questão inerente ao direito, inatingível pela lógica formal (MULLER, pp. 25, 26 e 193). Isso corrobora com a ideia de que todo texto normativo sempre possui carga de generalidade, variável gradativamente.

Em decorrência, se a abertura da Constituição sofre influência da normatividade dos princípios, duas são as respostas possíveis: 1). Os princípios possuem generalidade na interpretação aplicativa, diferenciando-se das regras nesse sentido como norma e não como texto normativo; 2) A influência dos princípios é funcional, permitindo maior adequação hermenêutica das normas infraconstitucionais à Constituição diante do caso concreto.

Para verificar cada uma das afirmativas acima, deve restar elucidada a distinção entre texto e norma no sentido de se mensurar, mesmo que de forma não exaustiva, a influência da generalidade do primeiro sobre a segunda. A partir de então, clarificada a influência da textura aberta sobre a nova visão do constitucionalismo, a influência funcional dos princípios sobre a constitucionalização será buscada em outros aspectos evitando confusões com a generalidade do texto.

Como a textura aberta é inerente a todo texto normativo que, de acordo com a concepção póspositivista, poder gerar na aplicação tanto uma regra como um princípio, deve ser verificada a questão da generalidade diretamente na norma em sua dinâmica de aplicação e não no texto. Ou seja, há generalidade na aplicação dos princípios distinta e independente da generalidade textual, já que esta também compõe a estrutura das regras? Somente focando na dinâmica de aplicação para além do texto poder-se-ia atribuir ao caráter aberto dos princípios influência sobre a constitucionalização. 


\section{Os limites textuais e materiais sobre a concretização da norma}

Para o prosseguimento da investigação, com o desiderato de levantar aspectos sobre a influência que a normatividade dos princípios exerce sobre constitucionalização hodierna do direito, clarificadora é a distinção entre norma e texto normativo. Focando as especificidades das normas constitucionais, a concepção póspositivista surgida a partir da distinção entre princípios e regras deslocará a abordagem para a dinâmica de concretização como caracterizadora da própria norma.

Apesar de apontados, no desenvolvimento da ciência jurídica, diversos critérios de distinção entre as espécies normativas, é justamente a concepção pós-positivista que trará foco na aplicação, diferenciando-se das concepções jusnaturalista e positivista, por conceituarem a norma de maneira estática, prendendo-a a análise do dispositivo legal.

Conforme visto, a distinção qualitativa das duas espécies normativas desloca a sua construção para o momento da aplicação, esbarrando assim na conclusão de que o dispositivo normativo não contém todos os elementos inerentes à norma. Por decorrência, a argumentação, entrelaçada ao enunciado, agregará conteúdos à norma, moldando-a às circunstâncias do momento de aplicação.

Robert Alexy apresenta o conceito semântico de norma, por meio do qual distingue os conceitos de norma de enunciado normativo. "A necessidade de se diferenciar entre enunciado normativo e norma pode ser percebida pelo fato de que a mesma norma pode ser expressa por meio de diferentes enunciados normativos." Sendo assim, a norma expressa um conteúdo deôntico a partir da interpretação de um enunciado normativo. "Uma norma é, portanto, o significado de um enunciado normativo." (ALEXY, 2008, p.54).

O Direito expressa sua força através das normas, sendo o enunciado parte da cadeia. "É recomendável, portanto, que os critérios para a identificação de normas sejam buscados no nível da norma, e não no nível do enunciado normativo. " As modalidades deônticas, como proibição e permissão, auxiliam na formulação de critérios de identificação de normas.

Quanto à identificação em um enunciado de seu caráter normativo, “(...) deve ser respondido que isso é possível com base em seu contexto. Por contexto devem ser entendidos não somente os outros enunciados que estão em conexão com esse enunciado, mas também seu uso, isto é, as circunstâncias e regras de sua utilização." (ALEXY, 2008, pp. 54 e 55). A contextualização feita por via processual de aplicação abrange alguns aspectos na reconstrução da norma advinda do enunciado.

No mesmo sentido, o professor Humberto Ávila ensina que:

A transformação dos textos normativos em normas jurídicas depende da construção de conteúdos de sentido pelo intérprete. Esses conteúdos de sentido, em razão do dever de fundamentação, precisam ser compreendidos 
por aqueles que os manipulam, até mesmo como condição para que possam ser compreendidos pelos seus destinatários. (ÁVILA, 2012, p.28).

Ou seja, sua atividade não se limita à descrição significações previamente existentes. Contudo, não se pode concluir pela inexistência de significados previamente determinados. O texto legal traz um sentido prévio. "Isso porque há traços de significado mínimos incorporados ao uso ordinário ou técnico da linguagem. " Por conseguinte, "há condições estruturais preexistentes no processo de cognição, que fazem com que o sujeito interprete algo anterior que se the apresenta para ser interpretado." (ÁVILA, 2012, pp.35 e 36). Fica claro que não obstante o dispositivo comporte pré-significações, há conteúdos que carecem de definição no iter da aplicação, por meio da contextualização.

Ao propor a Teoria Estruturante do Direito, Friedrich Müller enfatiza a importância da superação da cisão entre ser e dever-se, demonstrando que as circunstâncias fáticas compõem a estrutura da norma. A este aspecto material da norma ele atribui o nome de âmbito normativo. $\mathrm{O}$ âmbito normativo, ou seja, os fatos relevantes à norma, é delimitado pelo programa normativo, definido como "resultado da interpretação de todos os dados linguísticos" (2009, p 305). Isso indica que o texto normativo funciona como referencial linguístico de interpretação para a construção da norma.

Sob a teoria estruturante, que visa superar a ideia de distinção entre texto legal e direito baseada naquela "diferença mais genérica entre letra e espírito", a normatividade, no caso, é materialmente determinada:

Para o processo de concretização, a norma aparece diferenciada de acordo com o âmbito normativo e com a ideia normativa fundamental do programa normativo. Principalmente no direito constitucional os pontos de vista da concretização devem frequentemente ser deduzidos do texto normativo apenas numa pequena escala. A aplicação, de modo decisivo, vai além do texto normativo; não vai, porém, além da norma, cuja normatividade concreta deve justamente ser salientada apenas para o caso particular. (MULLER, 2009, p.197).

Destarte o texto possui um papel de referencial interpretativo do programa normativo. Isso não significa um papel de precedência, já que o próprio programa normativo se define simultaneamente ao âmbito normativo em sua materialidade. Juntos, limitando-se, constroem a normatividade.

Adotando a proposta estruturante, percebe-se que a normatividade, seja de princípios ou de regras, se faz concreta a partir do texto e dos fatos particulares levados à interpretação. Os fatos não carregam generalidade, pois são concretos, individualizados. Sendo assim, se os princípios possuem generalidade diversa daquela inerente a todo texto, esta teria que encontrar-se nos métodos de interpretação. Outrossim, a importância do aspecto material para a normatividade aponta para a distinção entre conteúdos como fator de relevância.

As disciplinas jurídicas, segundo Müller, apresentarão diferentes estruturas normativas de acordo com as diferenças materiais. "Por isso o direito público e o direito constitucional são em grau especialmente elevado 
direito político." O que se considera como matéria constitucional, na organização da sociedade política e do ordenamento, ultrapassa a simples ideia de hierarquização de normas.

À amplitude e à dinâmica da sua área de regulamentação corresponde uma abertura estrutural particularmente nítida das suas prescrições extremamente distintas quanto à densidade normativa, bem como material e quanto à concreção. A finalidade global do direito constitucional caracteriza também as normas de direitos fundamentais, que estão - em que pese o seu teor material peculiar - asseguradas no quadro da constituição e não podem ser concretizadas como leis técnicas especiais. (MÜLLER, 2009, p. 45).

Isso remonta à primeira questão. Os elementos passíveis da interpretação concretista não imprimirão aos princípios uma generalidade específica suficiente para distingui-los das regras. Tanto o texto quanto o conteúdo material constitucional são fontes de regras e princípios.

Eliminando as diferenciações a partir do texto e dos fatos, comuns às regras e princípios, a distinção somente poderá ser alocada na interpretação. Em outros termos, tendo o programa normativo como resultado da interpretação de determinado conjunto textual e fático, voltada à construção de um princípio ou de uma regra. A própria interpretação determinará qual das espécies será a norma resultante.

Portanto, a ideia de delimitação de conteúdos pelo programa normativo dependerá da materialidade normativa nos fatos e dos métodos interpretativos utilizados. Uma diferenciação funcional entre princípios e regras remeteria a uma consideração da carga axiológica na própria escolha de qual espécie normativa deverá ser utilizada a partir do texto diante do contexto.

Ora, o que não pode ser olvidado é o fato de que os dispositivos que servem de ponto de partida para a construção normativa podem germinar tanto uma regra, se o caráter comportamental for privilegiado pelo aplicador em detrimento da finalidade que lhe dá suporte, como também podem proporcionar a fundamentação de um princípio, se o aspecto valorativo for autonomizado para alcançar também comportamentos insertos noutros contextos. (ÁVILA, 2004, p. 62).

Ao contrário do que é colocado por Humberto Ávila, a teoria estruturante não atribui à escolha do aplicador a concretização da norma e, tampouco atribui ao texto o papel de ponto de partida, combatendo a ideia de precedência. Os aspectos materiais delimitam a interpretação do texto, que simultaneamente adequa os fatos à normatividade construída. O preenchimento dos conteúdos textuais não é estático, variando de acordo com as circunstâncias fáticas e a elas impondo recortes.

A definição de qual espécie normativa predominará em um caso concreto, quando pretende legitimação pela correspondência a um texto legal, se perfaz na dinâmica dos seus elementos. Nesse processo dinâmico são determinantes o aspecto material, o referencial legal e a interpretação, sem relações de precedência entre os elementos.

\section{O papel da interpretação na construção da norma}


Prosseguindo com o objeto principal deste trabalho, há que se buscar a clarificação de como funciona a cognição da norma diante do desenvolvimento das próprias teorias do conhecimento. Isso porque somente compreendendo os mecanismos da apreensão dos significados e os limites da objetividade na interpretação é que se pode elucidar, mesmo que brevemente, as características possíveis dos princípios como normas.

Para tanto, a ontologia de Heidegger, ao tratar do ser e do tempo, insere na compreensão a existência dos intérpretes:

Eis que a compreensão não é uma ação de um sujeito cognoscente que vai conhecer o mundo como seu objeto de estudo. O idealismo cartesiano de fundação de uma consciência que se constitui como um "olho que observa o mundo", que constitui uma razão que atrai e reduz tudo ao sujeito que conhece, tal como em Kant e Hegel, nem de longe está presente em Heidegger. (...). Logo, a compreensão não se submete a métodos, não se reduz ao projeto de matematização desse mundo, pois a compreensão não é um processo que dependa exclusivamente do homem. (...) A compreensão compõe o homem como uma abertura que o Dasein tem para se apropriar do mundo e ser também apropriado por ele. (CRUZ, 2011, p. 129).

Mesmo percebendo os limites da razão e da técnica, Heidegger não afirma pela impossibilidade da compreensão através da utilização de métodos. "Ele apenas sustenta que o método somente se aplica naquilo que o círculo hermenêutico permite, ou seja, se você já sabe de antemão a resposta." (CRUZ, 2011, p. 131).

Como visto, a determinação da espécie normativa não comporta uma resposta aferível de antemão, somente a partir do texto. Assim, as classificações, por implicarem em uma necessária redução, devem ser problematizadas. O papel do aprendizado e do passado deve ser revisto em um planejamento humanizado, considerando suas limitações:

Contudo, tal não se dá no campo jurídico pela aplicação de métodos de interpretação, sejam eles clássicos ou contemporâneos, isso porque eles se apresentam como um esforço inútil de controle da compreensão pela razão. (...). Tal observação, por outro lado, não impede a formação de standards, sejam na forma de precedentes ou princípios, pois esses representam a capacidade do sistema jurídico de aprender com seus erros." (CRUZ, 2011, pp. 131 e 132).

Para que seja possível trabalhar a normatividade dos princípios considerando a fenomenologia, pertinente mencionar que a compreensão se perfaz por aberturas do Dasein, as quais Heidegger dá o nome de existenciais. O primeiro é o da compreensão que, como abertura existencial do próprio intérprete diante do mundo desacorrentado do subjetivismo antagonizado da metafísica, funciona estruturalmente no ser, sempre como possibilidade "a partir do que the é dado como 'ser-lançado'. A compreensão é sempre comprometida com a possibilidade." (CRUZ, 2011, p. 132).

O segundo existencial é a "situação afetiva ou a disposição do sentimento", que envolve os aspectos além dos sentidos e da razão, o que impede a desconsideração do fator emociona-afetivo dos intérpretes como parte da 
concretização normativa. Afeta não somente os aspectos axiológicos, mas toda a compreensão da norma e do direito. "A compreensão se dá sempre diante da situação afetiva, da forma pela qual o Dasein percebe o mundo." (CRUZ, 2011, p. 133).

O terceiro existencial heideggeriano é a presença do outro, "pois o Dasein é sempre um 'ser-junto-aooutro', um Mitsein", restando "evidente que aquilo que the é dado perceber é sempre uma construção intersubjetiva e anônima." A presença do outro já impõe as condições de diálogo. (CRUZ, 2011, pp. 135 e 136). Isso leva ao entendimento que a intersubjetividade processual é fator determinante da normatividade. Também se reflete pela maneira como o julgador lida com a responsabilidade sobre os destinatários do provimento, influindo diretamente na normatividade aplicada.

Exemplo interessante que se tem para esse modo de responsabilidade é a conduta judicial diante de demandas relativas a direitos sociais, em especial os relativos ao direito de saúde. Nas demandas de natureza individual, o juiz se coloca diante da face do reclamante que expóe seu medo de morrer ou de sofrer. O juiz se torna refém de sua responsabilidade como condição existencial e dificilmente deixará de conceder o pedido. Contudo, caso a demanda seja uma ação coletiva, na qual a demanda da face se distancia, sua reação enfraquece sua responsabilidade, e ele assume uma postura que considera mais 'técnica' e 'racional' e, então, sente-se desobrigado a conceder o pedido. Observe que não se está examinando se de fato o autor tem ou não razão naquilo que pede, mas como sua disposição afetiva e sua compreensão se ligam com sua responsabilidade. (CRUZ, 2011, p. 139).

Outro aspecto relevante trazido pela fenomenologia à ideia de compreensão, gerando repercussões significativas no elemento normativo da interpretação, encontra-se na nova perspectiva do tempo kairológico. Como as aberturas existenciais do Dasein fazem com que sua existência seja aberta e reconstruída a todo momento, "passado, presente, futuro, 'ser-sido', 'ser-aí e o 'por-vir' não se dão linearmente." O tempo deixa de ser uma sucessão de agoras linear para se tornar uma dinâmica de realização do próprio Dasein. (CRUZ, 2011, pp. 144 ess.).

Assim, as informações do passado, como texto, contextos e fatos, misturam-se a outros elementos da compreensão, tomando feições variáveis. O mesmo fato não carregará um significado absoluto válido para todas as vezes em que for interpretado. Tampouco os textos normativos carregarão tais linhas exatas e absolutas. Da mesma maneira, o futuro como um 'por-vir', diante do 'ser-jogado', sofrerá influência e determinará a construção normativa em sua normatividade.

Considerando a interpretação como fator determinante da normatividade, sob a perspectiva fenomenológica de Heidegger, qualquer tentativa de realização da ideia de segurança jurídica como previsibilidade de resultados deve ser descartada e os métodos de interpretação problematizados. 
Assim, mais relevante se mostram as características da disciplina do Direito Constitucional do que os traços prescritivos do texto normativo, que tomará suas reais feições apenas diante de todos os elementos formadores da compreensão.

\section{NORMA CONSTITUCIONAL E SUA INTERPRETAÇÃO}

A normatividade constitucional carrega em sua estruturação peculiaridades que influenciam, por sua materialidade específica, na concretização do direito. "Quatro delas merecem referência expressa: a) superioridade hierárquica; b) a natureza da linguagem; c) o conteúdo específico; d) o caráter político." (BARROSO, 2009b, p.111).

A superioridade hierárquica torna as normas constitucionais como referenciais de aplicação de todas as demais normas do ordenamento. Contudo, não se pode atribuir unicamente à hierarquia textual como único fator de fundamentalidade dos preceitos constitucionais. Na aplicação, a superioridade deve ser aliada a posturas interpretativas de concretização dos princípios para que tenha normatividade, escapando da ideia de programas normativos voltados ao futuro.

Sobre a natureza da linguagem, por tratar-se da norma fundamental, traça as diretrizes básicas da atividade normativa de um Estado. Possui dispositivos normativos compostos por textos e expressões abertas, com conceitos que comportam interpretações mais amplas (BARROSO, 2009b, p.111). Isso influi diretamente no aspecto material da normatividade.

O texto constitucional também enseja normas bem específicas, cujo conteúdo é essencialmente constitucional. Assim são, por exemplo, as normas de organização, as ditas programáticas, (BARROSO, 2009b, pp.112 e 113) os princípios inerentes à formação e funcionamento do Estado, os direitos fundamentais em sua eficácia horizontal, entre outras cobertas pelo sentido material de constituição.

"Por fim, as normas constitucionais são políticas quanto à sua origem, quanto ao seu objeto e quanto aos resultados de sua aplicação. De fato, a Constituição resulta do poder constituinte originário, tido como poder político fundamental. " Todo o exercício de poder político do Estado passará pela regulamentação constitucional. Exatamente por isso que o controle de constitucionalidade judicial apresentará sempre um matiz político (BARROSO, 2009b, p.114).

Todas as peculiaridades apontam para uma interpretação mais receptiva aos argumentos externos ao direito e suas técnicas. Como explanado, a construção da norma é um exercício interpretativo de contextualização, que envolve elementos variados em sua dinâmica. Por conseguinte:

Há sempre que interpretar a Constituição como há sempre que interpretar a lei. Só através desta tarefa se passa da leitura política, ideológica ou simplesmente empírica para a leitura jurídica do texto constitucional, seja ele 
qual for. Só através dela, a partir da letra, mas sem se parar na letra, se encontra a norma ou o sentido da norma. (MIRANDA, 2007, p.448, grifos).

Em que pese "condicionalismos e fins políticos" inerentes do texto constitucional, que não podem ser olvidados na sua aplicação, a interpretação constitucional é jurídica e não se difere neste ponto dos demais ramos do Direito. Ou seja, deve ser tratado o seu texto como enunciado normativo, e sua aplicação como norma. (MIRANDA, 2007, p.451). Sendo assim, pertinente tratar dos métodos de interpretação apontados pela doutrina.

O primeiro é o método jurídico, ou hermenêutico clássico. Utiliza-se dos cânones tradicionais (lógicogramatical, sistemático, histórico, teleológico, etc.). Prima pela imparcialidade e literalidade, em perspectiva estática do texto interpretado. (FERNANDES, 2010, p. 171).

Diferentemente, no método tópico-problemático, há abertura na construção do conteúdo pela interpretação, caracterizando-se pela praticidade ligada ao caso concreto. A problematização prima pela argumentatividade plúrima, visando a solução mais adequada do problema posto.

Pelo método hermenêutico-concretizador, a norma deverá ser concretizada pelo intérprete, como em qualquer outro texto, lançando mão de pré-compreensões, "sempre e a partir de uma situação histórica concreta." Diferencia-se do método tópico, por ter o texto constitucional como ponto de partida e limite, em abordagem eminentemente dogmática. (FERNANDES, 2010, pp. 172 e 173).

O método científico-espiritual, ou método valorativo, sociológico, "atesta que a Constituição deve ter em conta as bases de valoração subjacentes ao texto", lançando mão das perspectivas política e sociológica para a preservação da unidade social. Posiciona o indivíduo em segundo plano para a integração social da comunidade.

De acordo com o método normativo-estruturante, devem ser investigadas as "funções de realização do direito constitucional" e analisada "a estrutura da norma a partir de uma conexão entre concretização normativa e funções jurídicas-práticas." Trata, portanto, da "implicação necessária entre preceitos jurídicos e a realidade a se regular", lançando mão de um universo linguístico-argumentativo, de bases jurídicas ou metajurídicas, para construção da norma. (FERNANDES, 2010, pp. 173 e 174).

Por fim, o método da comparação constitucional e a sociedade aberta de intérpretes da Constituição, de Peter Häberle, que não detém qualquer independência metodológica, advoga pela pluralidade de intérpretes, comparação de contextos e ordenamentos e a abertura "no processo de concretização e densificação das normas constitucionais". (FERNANDES, 2010, p. 175).

O rol de métodos acima, não exaustivo, demonstra a necessidade de problematização da construção normativa. Como visto, a distinção entre princípios e regras não está no texto e tampouco nos fatos, sendo fruto da compreensão da norma pela interpretação. Adotar o entendimento de que os princípios se miram imediatamente a um fim é mais uma questão de método de compreensão do programa normativo do que uma questão textual. 
Isso direciona para a conclusão de que os princípios e as regras somente existirão se essa classificação for utilizada como método de concretização. Mesmo o texto, que seria o único elemento com certa carga de précompreensão, pela kairologia, não porta significados absolutos. Por isso, não se pode pretender que os princípios existam antes da atividade de estruturação.

Destarte, a normatividade dos princípios não aparece unicamente através da sua inserção na constituição, em decorrência do seu posicionamento hierárquico superior, mas sim pela adoção do método passou a considerar sua eficácia imediata diante do horizonte de interpretação, decorrente do desenvolvimento do constitucionalismo hodierno.

\section{CONCLUSÃO SOBRE A NORMATIVIDADE DOS PRINCÍPIOS NA CONSTITUCIONALIZAÇÃO E SUA EFETIVIDADE}

A superioridade hierárquica reclama a observação do texto constitucional na concretização das normas infraconstitucionais. Sob uma aplicação positivista pautada na mera subsunção entre fato e texto na produção da norma, a adaptação do texto infraconstitucional ao contexto material da Constituição restaria limitado pela própria natureza ampla inerente ao conteúdo do direito constitucional como ramo jurídico. A generalidade do texto constitucional colocaria sua realização em posição subsidiária à adequação entre norma infraconstitucional e fato, como valores de preenchimento de lacunas.

Sob o prisma da bipartição das normas em princípios e regras, a aceitação da formação princípio lógicanormativa a partir de qualquer enunciado textual, como propõe Humberto Ávila, permitiria, sob um primeiro olhar, a consideração deôntica do texto constitucional na concretização de qualquer norma infraconstitucional do ordenamento. Isso em razão da possibilidade de se buscar, por meio da interpretação teleológica, o fim da norma constitucional, desprendendo-se da literalidade textual e facilitando a consideração das dimensões axiológica e material da norma.

Neste ponto, a utilização da concretização de princípios altera a relação entre norma e enunciado, pois de acordo com a distinção pela priorização da conduta no caso das regras, e do fim a ser atingido no caos dos princípios, as primeiras restringem-se aos aspectos gramaticais do enunciado, enquanto os segundos aos aspectos teleológicos. Sob esse foco, a adoção da normatividade dos princípios ampliaria a eficácia imediata das normas constitucionais, por dar ao aplicador a possibilidade de ultrapassar a literalidade prescritiva não somente do texto superior, mas também da norma infraconstitucional a ele confrontada.

Porém, não se pode descurar de algumas observações. A primeira diz respeito ao fato de que muitos textos carregam enunciados carentes de prescrições descritivas, o que impossibilitaria a aplicação como regras pelo método proposto. São situações em que a interpretação teleológica necessariamente deverá preceder à 
formulação de uma conduta. Lado outro, nos enunciados descritivos, considerando que o ordenamento deverá preservar sua unidade, a escolha pela precedência da conduta poderá desembocar em diversos fins, negligenciando a consideração do horizonte hermenêutico para a busca da resposta mais adequada na adoção de uma resposta predeterminada textualmente, retrocedendo ao positivismo abstrativista e não problematizado.

A isso se acresce a noção de tempo kairológico. $\mathrm{Na}$ compreensão não há precedência entre os existenciais heideggerianos. Ao mesmo tempo, a dinâmica de compreensão não comporta a pretensa objetividade de aplicação das regras em detrimento do contexto sob a justificação de buscar-se segurança jurídica na previsibilidade de resultados.

Em suma, tanto os fins das normas quanto o teor gramatical do texto se determinam simultaneamente, sendo a influência da valoração do conteúdo constitucional sobre as demais disciplinas mais uma questão de evolução do constitucionalismo do que de normatividade dos princípios.

Na prática, tanto os fins do direito global como ordenamento quanto os teores linguísticos do texto são considerados simultaneamente, sendo que a pretensão de decidibilidade, a justificação e o dever que instituem as normas não podem diferenciá-las pela precedência dos fatores descrição de conduta e fim a ser atingido. A construção da normatividade pelo processo envolve a interpretação simultânea de vários textos em um mesmo contexto, para a criação de um único provimento que conterá uma ou mais normas individuais. Nenhuma das normas individuais de uma única sentença, por exemplo, pode ser definida isoladamente, sob pena de contradição lógica. Afinal, são compreendidas no mesmo contexto de aplicação, pelos mesmos aplicadores.

O caráter de fundamentalidade dos princípios apontado por Canotilho não escapa às demais normas de uma Constituição. Se em alguma circunstância o texto é aplicado diretamente em sua literalidade, como prescrição organizativa ou de conduta, isso não pode contrariar os fins principais e os valores de todo o conjunto normativo-constitucional. Os valores constitucionais devem compor o discurso decisório como pressupostos de legitimidade tanto na aplicação de princípios quanto de regras.

Vistos como standards de argumentação, os princípios funcionam como construções que aproximam o conteúdo axiológico do texto constitucional, fornecendo limites linguísticos, mesmo que ainda amplos, à concretização das normas infraconstitucionais. Apesar da variação com que o preenchimento dos seus conteúdos pode tomar em cada contexto, o enfrentamento dos preceitos constitucionais vincula a autoridade e não pode deixar de ser feito. Nesse ponto, a positivação dos princípios atua como limitador dos aspectos axiológicos determinando parâmetros, ainda que amplos, a serem observados necessariamente.

Portanto, para a consideração dos princípios como normas diferentes das regras, é necessária a aceitação destas últimas presas aos moldes de aplicação mecânica. Se os princípios são normas que consideram valores, fins 
a serem atingidos e desprendimento das prescrições descritivas, as regras, em contrapartida, não terão essas características. Somente assim se sustenta a bipartição das espécies.

Por conseguinte, diante da perspectiva de compreensão fenomenológica, como aceitar a existência de regras nos moldes apresentados, presas à segurança jurídica como previsibilidade decisória material? Isso levaria a uma abertura não problematizada da utilização de determinada espécie normativa (regras) sem uma justificação adequada para a escolha desta espécie, funcionando a opção como fundamento em si mesmo, ocultando as reais razões da escolha por essa espécie (regras) e não pela outra (princípios).

O que se defende aqui é que tanto as regras quanto os princípios devem ser aplicados da mesma maneira, considerando o fim do ordenamento, os valores pertinentes, sem a prevalência literal do texto como fonte de previsibilidade de resultados. Nesse passo, as diferenciações entre as espécies passam a ter seu sentido fragilizado.

$\mathrm{Na}$ prática, todas as diferenciações propostas levam à ideia de que os princípios permitiriam maior desprendimento da literalidade do texto, enquanto as regras não. Aceitar a distinção das duas espécies, em suma, permite ao aplicador justificar o desprendimento através da simples alegação de que no caso trata-se de um princípio e não de uma regra, ocultando demais fatores inerentes à concretização, como a influência dos existenciais, dificultando, dessa forma, a fiscalização do seu iter decisório.

Diante das reflexões expostas, conclui-se que não é a aquisição de normatividade pelos princípios como espécie normativa fator de abertura ou adequação do texto constitucional à realidade, tampouco facilitador da adequação entre normas infraconstitucionais e texto constitucional. Na verdade, a influência da Constituição nos demais ramos está atrelada diretamente à evolução da hermenêutica constitucional hodierna.

\title{
THE NORMATIVITY PRINCIPLES ON THE CONSTITUCIONALIZATION OF LAW
}

\begin{abstract}
This article aims to analyze the differences between the normativity of principles and rules, as distinguishing criteria indicated by the theories that adopt this division and relate to them as a mechanism of constitutionalization of law. Therefore, beyond the criteria of distinction, describes the evolution of concepts under which the principles were developed: natural law, positivism and post-positivism. Then, seeking to distinguish sources determinants to normative concretization, are analyzed the normative text, materiality and interpretation. For both are considered as theoretical frameworks Theory Structuring the Right of Friedrich Müller and Heidegger's ontology. Made the general considerations about the structure of norms, points out some specific features of constitutional norms and its legal branch. Finally, the conclusion seeks to verify the compatibility between the conceptualization of the principles as a kind of norm and its influence on the interpretation and implementation of the Constitutional Law.
\end{abstract}

Keywords: Normativity. Principles. Materiality. Structuring Theory. Constitutionalization. 


\section{REFERENCIAS}

ALEXY, Robert. Teoria dos direitos fundamentais. Tradução de Virgílio Afonso da Silva da $5^{a}$ edição alemã. São Paulo: Malheiros, 2008.

ÁVILA, Humberto. Teoria dos Princípios: da definição à aplicação dos princípios jurídicos. 13a ed. rev. e ampl. São Paulo: Malheiros, 2012.

BARROSO, Luís Roberto. Curso de direito constitucional contemporâneo: os conceitos fundamentais e a construção do novo modelo. São Paulo: Saraiva, 2009.

Interpretação e aplicação da constituição: fundamentos de uma dogmática constitucional transformadora. São Paulo: Saraiva, 2009b.

BOBBIO, Norberto. O positivismo jurídico: lições de filosofia do direito; compiladas por Nello Morra; tradução e notas Márcio Pugliesi, Edson Nini, Carlos E. Rodrigues. - São Paulo: Ícone, 1995.

Teoria da norma jurídica. Trad. Fernando Baptista e Ariani Bueno Sudatti. 4 ed. revista. Bauru: Edipiro, 2008. Título original: Teoria della norma giuridica (G. Giappichelli Editore, Torino, 1993).

BONAVIDES, Paulo. Curso de direito constitucional. 23a ed. ataul. e ampl. São Paulo: Malheiros, 2008.

CANOTILHO, José J. Gomes. Direito constitucional e teoria da constituição. $5^{\text {a }}$ ed. Coimbra: Almedina, 2002.

CRUZ, Álvaro Ricardo de Souza. A resposta correta - incursões jurídicas e filosóficas sobre as teorias da justiça. Belo Horizonte: Arraes Editores, 2011.

DWORKIN, Ronald. Levando os direitos a sério. Tradução e notas Nelson Boeiro. São Paulo: Martins Fontes, 2002.

FERNANDES, Bernardo Gonçalves. Curso de direito constitucional. 1 Ed. - Rio de janeiro: Lumen júris, 2010.

FERRAZ JUNIOR, Tercio Sampaio. Introdução ao estudo do direito: técnica, decisão, dominação. 4. ed. São Paulo: Atlas, 2003.

KELSEN, Hans. Teoria geral das normas. Tradução de José Florentino Duarte. Porto Alegre: Fabris, 1986.

HART, H. L. A. O conceito de direito. Tradução A. Ribeiro Mendes. 3 ed. Lisboa: Fundação Calouste Gulbenkian, 2001.

MATOS, Aníbal Magalhães da Cruz. Conflitos entre princípios constitucionais: elementos teóricos para uma compreensão adequada ao Estado Democrático de Direito. Orientador: Alexandre Travessoni Gomes. Dissertação (Mestrado) - Pontifícia Universidade Católica de Minas Gerais. Programa de Pós-Graduação em Direito. Belo Horizonte, 2010.

MENDES, Gilmar Ferreira; COELHO, Inocêncio Mártires; BRANCO, Paulo Gustavo Gonet. Curso de direito constitucional. $4^{a}$ ed. rev. e atual. São Paulo: Saraiva, 2009 
MIRANDA, Jorge. Teoria do Estado e da constituição. Tradução da edição protuguesa. Rio de Janeiro: Forense, 2007.

MÜLLER, Friedrich. Teoria estruturante do direito. Tradução Peter Naumann, Eurides Avance de Souza. 2 ed. rev., atual. e ampl. - São Paulo: Editora Revista dos Tribunais, 2009.

PEREIRA, Rodolfo Viana. Hermenêutica filosófica e constitucional. Belo Horizonte: Del Rey, 2001.

Trabalho enviado em 03 de fevereiro de 2015.

Aceito em 24 de março de 2015. 